\title{
A new paradigm for obtaining marketing approval for pediatric-sized prosthetic heart valves
}

\author{
Ajit P. Yoganathan, PhD, ${ }^{\mathrm{a}}$ Mark Fogel, MD, ${ }^{\mathrm{b}}$ Susan Gamble, BS, MBA, ${ }^{\mathrm{c}}$ Michael Morton, MA, ${ }^{\mathrm{d}}$ \\ Paul Schmidt, MS, ${ }^{\mathrm{c}}$ Jeff Secunda, MS, MBA, ${ }^{\mathrm{e}}$ Sara Vidmar, MBA, ${ }^{\mathrm{d}}$ and Pedro del Nido, $\mathrm{MD}^{\mathrm{f}}$
}

\begin{abstract}
Objective: Congenital heart valve disease is one of the most common abnormalities in children. There are limited technological solutions available for treating children with congenital heart valve diseases. The aim of this study is to provide the details of the consensus reached in terms of pediatric definitions, design approach, in vitro testing, and clinical trials, which may be used as guidance for developing prosthetic heart valves for the pediatric indication.

Methods: In stark contrast to the various designs of adult-sized replacement valves available in the market, there are no Food and Drug Administration (FDA)-approved prosthetic heart valves available for use in the pediatric population. There is a pressing need for FDA-approved pediatric valve devices in the United States. The pediatric patient population has been typically excluded from replacement heart valve trials for several reasons. In January 2010, heart valve manufacturers and pediatric clinicians collaborated with academicians and FDA staff in a workshop to suggest ways to successfully evaluate pediatric prosthetic valves and conduct pediatric clinical trials to provide acceptable heart valve replacement options for this patient population.
\end{abstract}

Results: Recommendations, derived from ISO 5840:2005 and the 2010 FDA Draft Replacement Heart Valve Guidance, are provided for hydrodynamic, durability, and fatigue testing.

Conclusions: The article specifically addresses in vitro and premarket and postmarket approval clinical studies that should be considered by a heart valve manufacturer for obtaining regulatory approval of pediatric sizes of prosthetic heart valve designs that are already approved for adult clinical use. (J Thorac Cardiovasc Surg 2013;146:879-86)

Congenital heart valve disease is one of the most common malformations in children. Valve disease in children and young adults can occur both on the systemic (commonly left) side of the heart and on the pulmonary (commonly right) side of the heart. Often, these valvular defects are not isolated, but are associated with significant additional structural defects, which may require extensive repair or intervention. The most common valve abnormalities seen in children include aortic stenosis, mitral stenosis, or regurgitation. Valvular regurgitation due to catheter-based or surgical intervention aimed at treating severe stenosis is the most common form of acquired valve defect in children and can involve the aortic, mitral, and pulmonary valves. Congenital tricuspid valve abnormalities are relatively uncommon but can present a significant challenge to the clinicians attempting repair.

\footnotetext{
From The Wallace H. Coulter Department of Biomedical Engineering, ${ }^{\text {a }}$ Georgia Institute of Technology and Emory University, Atlanta, Ga; The Children's Hospital of Philadelphia, ${ }^{\mathrm{b}}$ Philadelphia, Pa; Edwards Life Sciences LLC, ${ }^{\mathrm{c}}$ Irvine, Calif; Medtronic, Inc, ${ }^{\mathrm{d}}$ Minneapolis, Minn; AdvaMed, ${ }^{\mathrm{e}}$ Washington, DC; and Boston Children's Hospital, ${ }^{\mathrm{f}}$ Boston, Mass.

Disclosures: Authors have nothing to disclose with regard to commercial support. Received for publication March 31, 2013; accepted for publication April 18, 2013; available ahead of print June 24, 2013.

Address for reprints: Ajit P. Yoganathan, PhD, The Wallace H. Coulter Department of Biomedical Engineering, Georgia Institute of Technology and Emory University, 313 Ferst Dr, Atlanta, GA 30332 (E-mail: ajit.yoganathan@bme.gatech.edu). $0022-5223 / \$ 36.00$

Copyright (c) 2013 by The American Association for Thoracic Surgery http://dx.doi.org/10.1016/j.jtcvs.2013.04.016
}

Pulmonary (or right-sided) defects of the heart are most often secondary to underdevelopment of portions or the entire right ventricular outflow tract, including the pulmonic valve. If severe, this can require placement of a conduit that will facilitate blood flow from the patient's right ventricle to the pulmonary arteries. Unfortunately, these conduits become dysfunctional rather quickly. Therefore, patients with conduits are subjected to multiple interventional and surgical procedures throughout their lifetime. Congenital isolated pulmonic valve stenosis can sometimes be treated percutaneously with balloon valvuloplasty. This technique, however, carries a risk that the treated valve will later become regurgitant and require surgical intervention. Defects involving the right-sided atrioventricular valve, most commonly the tricuspid valve, are fortunately rare and include Ebstein anomaly. Repair and replacement of this valve continue to be significantly challenging.

Managing patients with systemic, left-sided, congenital heart valve disease, including aortic stenosis and mitral valve stenosis or prolapse (also pediatric rheumatic fever in developing countries), poses significant challenges for physicians. There are limited technological solutions available for these patients. Commercial bioprosthetic valves for aortic and mitral valve replacement may not be available in sizes that are appropriate for infants and children. Few replacement heart valves are indicated for pediatric patients. 

Abbreviations and Acronyms
AVR $=$ aortic valve replacement
AWT $=$ accelerated wear testing
DFM $=$ dynamic failure mode
$\mathrm{EOA}=$ effective orifice area
FDA $=$ Food and Drug Administration
$\mathrm{HVG}=$ heart valve guidance
ISO = International Standards Organization

Figure 1 shows the distribution of valve procedures performed at Children's Hospital Boston (Boston, Mass) during a 5-year period (2005-2010). Most of the procedures performed involve reconstruction of the native valve, often with the use of autologous or xenograft material, despite the fact that most valve repair operations in children are palliative and will require further reconstruction or, ultimately, replacement.

The clinical impact of congenitally deformed valves is significant and often lifelong. Treatment decisions are almost always affected by the effects of rapid somatic growth, active lifestyle, and accelerated deterioration of biological prostheses.

Furthermore, pediatric valve replacement is a high-risk procedure with higher operative mortality, reoperation rate, and late morbidity compared with adult patients undergoing the same operation. The reasons for the higher operative mortality are multiple and complex. Most often, the available prosthesis is too large for the child's anatomy, resulting in delay in referral for surgery, and when surgery is undertaken, additional steps are often required to enlarge the site of implantation to accommodate the prosthesis. These enlargement procedures carry additional risk of injury to adjacent structures, such as specialized cardiac conduction tissue, coronary arteries, and atrial and interventricular septa.

An example of the early and late outcomes of aortic valve replacement (AVR) in children is provided in the study by Karamlou and colleagues, ${ }^{1}$ in which they performed competing risk analysis of 2 mutually exclusive risk factors after AVR, death, and prosthesis replacement in 160 children. The authors analyzed the use of mechanical valves and bioprosthetic valves. Of 185 total AVR episodes in which a type of the implanted valve was documented, mechanical valves were implanted in 94 patients (BjorkShiley, St Jude Medical, Carbomedics, and others). The authors' analysis showed that, after 10 years from initial AVR, 19\% of patients had died without a second AVR, $34 \%$ underwent a second AVR, and only $47 \%$ remained alive without repeated replacement (Figure 2).

Similar results have been reported for mitral valve replacement in children with operative mortality ranging from $4 \%$ to $7.4 \%$, approximately double that reported for similar procedures in adults. The long-term results also indicate a continuing risk of death or need for reoperation for valve re-replacement (Figure 3).

\section{AVAILABLE VALVE PROSTHESES FOR PEDIATRIC USE}

Although there are many types of replacement heart valves available on the market for adult patients, the same is not true for pediatric patients. Clinical studies have routinely been conducted on the adult patient population, excluding pediatrics. The pediatric patient population has been typically excluded from replacement heart valve trials for several reasons, some of which include the following:

- Limited patient pool requiring a replacement heart valve that can lead to prolonged recruitment to achieve required enrollment numbers

- Complex health histories (of which many lead to early mortality)

- Comorbidities can confound the adverse event profiles for the study, making it difficult to assess the overall safety of the valve

- Limited valve sizes available

- In addition, after valve replacement, the pediatric patient continues to grow, ultimately necessitating reoperation and the placement of a larger valve

- Uniformity of an identifiable patient population is extremely challenging to achieve, again leading to prolonged study recruitment

\section{Collaboration Among Heart Valve Manufacturers, Pediatric Clinicians, Academicians, and FDA}

In 2008, the US Food and Drug Administration (FDA) leadership contacted the heart valve industry to suggest that FDA and industry might collaborate to develop a least-burdensome approach to making pediatric heart valves available in the marketplace. In January 2010, heart valve manufacturers and pediatric clinicians collaborated with academicians and FDA during a workshop to suggest ways to successfully design and evaluate pediatric prosthetic valves and conduct pediatric clinical trials to provide acceptable heart valve replacement options for this patient population. Consensus was achieved with respect to the pediatric definition, design philosophy, appropriate in vitro testing, ${ }^{2}$ and criteria for conducting a clinical trial. ${ }^{3}$ This article provides the details of the consensus reached, which may be used as guidance for developing prosthetic heart valves for a pediatric indication. This collaboration between heart valve manufacturers, pediatric clinicians, academicians, and the FDA would likely lead to increased availability of pediatric devices in other regulated regions.

\section{Pediatric Patient Population}

Pediatrics include neonates (newborns), infants, toddlers, children, and adolescents. These subpopulations can be 


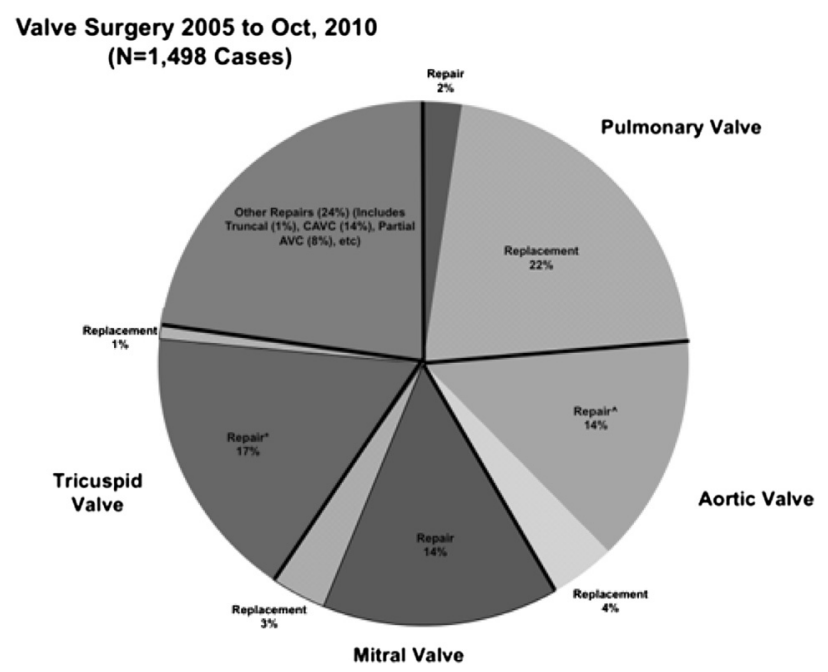

FIGURE 1. Distribution of valve surgical procedures performed at 1 center (Children's Hospital Boston, Boston, Mass) over a 5-year period. CAVC, Complete atrioventricular canal; $A V C$, atrioventricular canal.

defined as shown in Table 1. The definitions are based on the information provided in the June 2003 Pediatric Expertise for Advisory Panels ${ }^{4}$ and recommendations from the pediatric clinicians in attendance at the 2010 workshop.

\section{Pediatric Design Approach}

The goal of the pediatric design approach is to provide additional options for the treatment of these patients based on known safety and effectiveness data of approved designs. Because the pediatric patient's heart valves are smaller than those of the adult patient, a logical approach would be to take a previously proven design and scale it down to fit

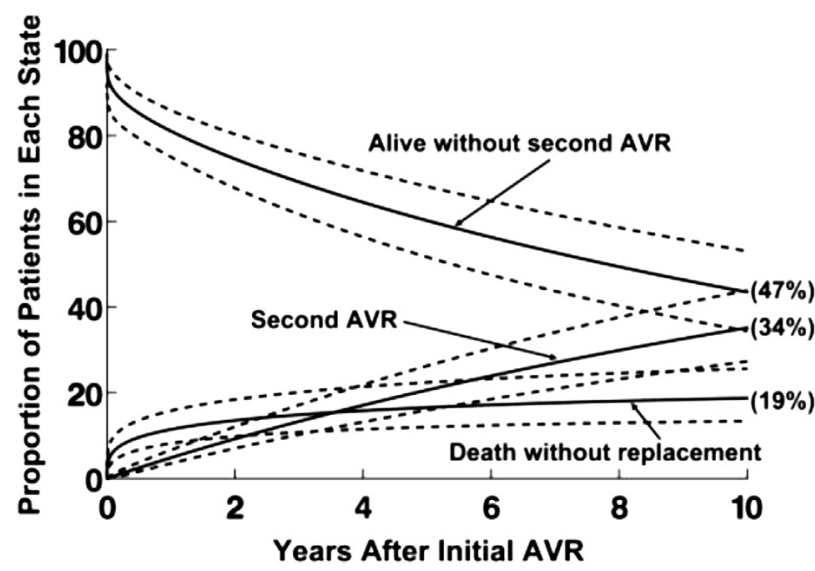

FIGURE 2. Competing-risks depiction of events after initial aortic valve replacement $(A V R)$ in 160 children. All patients are represented in the graph as alive at the initial AVR and thereafter migrate to 1 of 3 mutually exclusive end states (death, subsequent AVR, or remaining alive without subsequent AVR) at a time-dependent rate defined by the underlying hazard functions. At any point, the sum of the proportion of children in each state is $100 \%$.

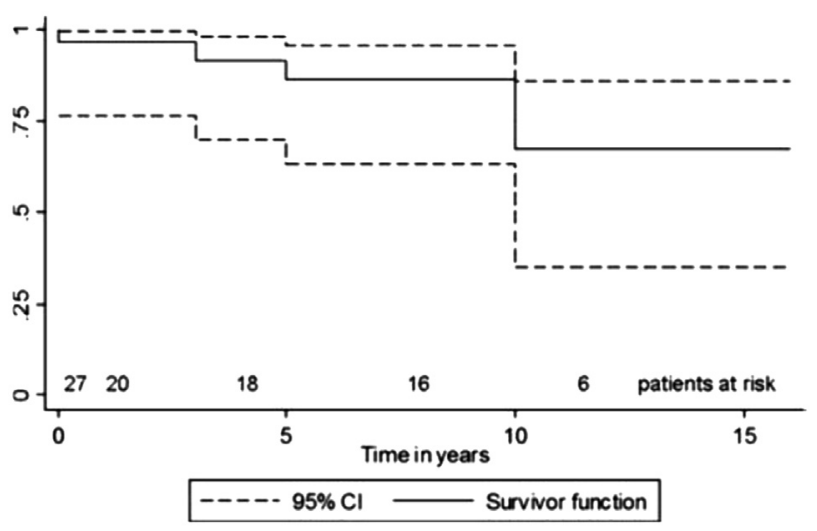

FIGURE 3. Freedom from reoperation for patients having valves implanted in the atrioventricular position. Numbers under the curve indicate patients at risk. $C I$, Confidence interval.

the smaller pediatric patient. All valve components would not necessarily be scaled linearly using a common factor, because some structural support components may have to be scaled differently from others to maintain a design and stress envelope consistent with the adult sizes and accommodating differing component material properties. Fit-up and dimensional tolerances are other examples of elements that may not scale linearly or in exact proportion to other component geometries.

The pediatric valve would use the same materials, be processed in the same way, and have a demonstrably similar geometry to a previously FDA-approved design. By using this approach, one would be starting with an established record of clinical safety and effectiveness, based on a clinically proven design, materials, and processing. It is anticipated that pediatric designs would typically involve scaling down the smallest approved adult-sized valve in a given design by 1 to 3 sizes. It is expected that the potential risks of the new pediatric size(s) would, therefore, be minimized, and that this rationale would allow for reduced clinical study requirements for the new heart valve sizes by leveraging existing safety and effectiveness data from already FDA-approved adult prosthetic heart valves. The following discussion of in vitro testing and clinical trials is based on this philosophy.

\section{In Vitro Data Required to Support a Premarket Approval Application}

The proposed engineering and testing paradigm for pediatric replacement heart valves is based on International Standards Organization (ISO) 5840:2005 (ISO 5840) ${ }^{5}$ and the 2010 FDA Draft Replacement Heart Valve Guidance (HVG). ${ }^{6}$ There is no significant reduction in the in vitro testing from these historic adult valve norms. Similar tests, sample sizes, and analyses are proposed as have been used for the approval of the current designs. Specific recommendations are provided for hydrodynamic, durability, 
TABLE 1. Pediatric subpopulations

\begin{tabular}{lll}
\hline $\begin{array}{c}\text { Pediatric } \\
\text { subpopulation }\end{array}$ & $\begin{array}{c}\text { Approximate } \\
\text { age range }\end{array}$ & \multicolumn{1}{c}{ Definition } \\
\hline Newborn & Birth to $1 \mathrm{mo}$ & $0<$ Age $<30 \mathrm{~d}$ \\
Infant & 1 mo to $1 \mathrm{y}$ & $30 \mathrm{~d} \leq$ Age $<1$ y \\
Toddler & $1-4 \mathrm{y}$ & $1 \mathrm{y} \leq$ Age $<5 \mathrm{y}$ \\
Child & $5-12 \mathrm{y}$ & $5 \mathrm{y} \leq$ Age $<13$ y \\
Adolescent & $13-21 \mathrm{y}$ & $13 \mathrm{y} \leq$ Age $<22 \mathrm{y}$ \\
\hline
\end{tabular}

and fatigue testing. There are 2 main differences from the proposed paradigm when compared with historic norms: testing conditions and position within the heart (because systemic and pulmonary pressures can differ significantly). First, as patient age and size decrease, there is a substantial increase in heart rate and systolic duration, coupled with a substantial decrease in cardiac output. These conditions vary with age and should be selected based on the target pediatric subpopulation. Second, the testing is intended to address both right- and left-sided heart valve replacement, which are of equal interest and need. Therefore, testing conditions and suggestions are provided for pulmonic and tricuspid valves, as well as for aortic and mitral valves.

Hydrodynamic testing. The ISO 5840 and HVG documents suggest that hydrodynamic tests be performed to characterize the behavior of a prosthetic heart valve. The recommended tests are provided in Table 2.

The specific recommended test conditions for the right and left sides of the heart are provided in Tables 3 and 4 as a function of the pediatric subpopulation group. The recommended values are based on handbook and literature data. ${ }^{7-11}$

TABLE 2. Hydrodynamic flow characterization tests

\begin{tabular}{|c|c|c|}
\hline Test & 1 Size down & $\geq 2$ Sizes down \\
\hline Steady backflow leakage & Recommended & $\begin{array}{l}\text { Recommended for } \\
\text { each size }\end{array}$ \\
\hline $\begin{array}{l}\text { Pulsatile flow pressure } \\
\text { decrease }\end{array}$ & Recommended & $\begin{array}{l}\text { Recommended for } \\
\text { each size }\end{array}$ \\
\hline $\begin{array}{l}\text { Pulsatile flow } \\
\text { regurgitation }\end{array}$ & Recommended & $\begin{array}{l}\text { Recommended for } \\
\text { each size }\end{array}$ \\
\hline Flow visualization & Recommended & $\begin{array}{l}\text { Recommended for } \\
\text { smallest size }\end{array}$ \\
\hline $\begin{array}{l}\text { Leaflet kinematic motion } \\
\text { analysis studies }\end{array}$ & Recommended & $\begin{array}{l}\text { Recommended for } \\
\text { each size }\end{array}$ \\
\hline Cavitation potential & $\begin{array}{l}\text { Justification with } \\
\text { experimental fluid } \\
\text { mechanics and } \\
\text { computational fluid } \\
\text { dynamics }\end{array}$ & $\begin{array}{l}\text { Justification with } \\
\text { experimental fluid } \\
\text { mechanics and } \\
\text { computational fluid } \\
\text { dynamics }\end{array}$ \\
\hline $\begin{array}{l}\text { Verification of Bernoulli } \\
\text { relationship }\end{array}$ & $\begin{array}{l}\text { Justification with } \\
\text { experimental fluid } \\
\text { mechanics and } \\
\text { computational fluid } \\
\text { dynamics }\end{array}$ & $\begin{array}{l}\text { New data for } \\
\text { smallest size }\end{array}$ \\
\hline
\end{tabular}

The hydrodynamic testing would be conducted as described in ISO 5840, with the exception of the test chamber diameter. Steady and pulsatile flow hydrodynamic tests, flow visualization, cavitation potential, and Bernoulli verification studies for pediatric-sized valves should be conducted in test chambers of appropriate geometry and size. Kinematic motion analysis studies should be conducted, demonstrating that the pediatric valve occluder moves in a similar way to the adult valve occluder (ie, open and close completely), under appropriate simulated physiological conditions.

Overall structural performance testing. The ISO 5840 and HVG documents suggest that several general tests and analyses be performed to characterize the structural integrity of a prosthetic valve. These categories are listed in Table 5.

AWT data. The ISO 5840 and HVG documents provide guidance on how to perform accelerated wear testing (AWT), or durability testing, to help characterize the structural integrity of a prosthetic heart valve. Recommendations for the specific pediatric AWT test conditions for the right and left sides of the heart are provided in Table 6 as a function of the pediatric subpopulation group. The recommended values are based on handbook and literature data. $^{7,8}$

Because children can quickly outgrow a replacement heart valve, the duration for AWT testing has been adjusted for the youngest subpopulations based on consideration of the guidance documents and the consensus of the workshop. Recommendations for the specific pediatric AWT duration are provided in Table 7 as a function of the pediatric subpopulation group.

Stress and fatigue life analyses. As part of structural performance characterization, the ISO 5840 and HVG documents require stress and life analyses for a prosthetic heart valve. The stress analysis typically requires input data from test measurements of device loading over the cardiac cycle. The fatigue life analysis typically requires fatigue data run under various stress conditions and run out to various numbers of cycles. The recommended test conditions for determining device loading in the stress analysis are provided in Table 8 . Table 8 also provides recommendations for the specific pediatric life analysis loading test conditions, as well as the life criteria as a function of the pediatric subpopulation group, based on consideration of the guidance documents and the consensus of the workshop participants.

As with all the in vitro tests, this approach to fatigue life analysis only applies to an existing, approved design that is scaled down to pediatric sizes, using identical materials.

There is no official FDA guidance for replacement heart valves. Nevertheless, the draft 1994 Replacement HVG and ISO 5840 provide useful information on approaches to fatigue testing/life analysis. In addition, the methods used 
TABLE 3. Steady backpressure and steady forward flow test conditions

\begin{tabular}{lccc}
\hline Pediatric subpopulation & $\begin{array}{c}\text { Steady forward flow rates, } \\
\text { L/min }\end{array}$ & $\begin{array}{c}\text { Left-sided heart steady } \\
\text { backpressure, } \mathbf{~ m m ~} \mathbf{H g}\end{array}$ & $\begin{array}{c}\text { Right-sided heart steady } \\
\text { backpressure, } \mathbf{~ m m ~ H g}\end{array}$ \\
\hline Newborn & $1.5,3,5,10$ & 40,80 & $5,10,20$ \\
Infant & $3,5,10,15$ & $40,80,120$ & $5,10,20$ \\
Toddler & $5,10,15,20$ & $40,80,120$ & $5,10,20$ \\
Child & $5,10,15,20,25$ & $40,80,120,160$ & $5,10,20,30$ \\
Adolescent & $5,10,15,20,25,30$ & $40,80,120,160,200$ & $5,10,20,30,40$ \\
\hline
\end{tabular}

to previously qualify the adult sizes of a particular design would also be appropriate to qualify the scaled pediatric sizes of the same design.

To impart a significant degree of conservatism into the analysis, the FDA has historically required that fatigue/ life analysis be applied to the "worst case," or the single most severe combination of all the factors that could contribute to fatigue. If the worst-case valve size can be shown to satisfy the fatigue life requirements, then all the other sizes will also meet the fatigue life requirements.

Approved designs that have previously identified the worst-case size and "passed" a rigorous life analysis can be scaled down to pediatric sizes, using identical materials. In this situation, it will be necessary to carefully perform a thorough stress analysis on each of the new pediatric sizes, based on new loading and/or deflection measurements of the new sizes. If the new stress analysis shows that the pediatric sizes are no worse than the previously identified worst case, then the pediatric size may also be considered to pass the life analysis.

Specifically, given a thorough damage-tolerant fatigue analysis based on material specimen testing and analysis, the previous material testing would apply and a new stress analysis showing that the pediatric sizes are not the worst case could be used to justify no additional damage-tolerant fatigue testing. Similarly, given a thorough stress/life fatigue analysis based on material specimen testing and analysis, the previous material testing would apply and a stress analysis showing that the pediatric sizes are not the worst case could be used to justify no additional stress/life fatigue testing. Finally, as long as a thorough stress analysis was performed on the adult sizes and the pediatric sizes, a similar justification could apply to the component testing approach. However, if component testing was previously performed for the adult sizes without a thorough stress analysis, then this justification would not apply.

DFM testing. The HVG document suggests that a selection of valves be tested to failure after AWT testing to determine the method in which the prosthetic heart valve will fail. If the stress analysis demonstrates that the new size is not the worst case, and if dynamic failure mode (DFM) testing will have already been performed for the larger sizes of the valve, it may be reasonable to forego additional DFM testing based on a scientifically valid justification.

If the new size(s) prove(s) to be the new worst case, it may be reasonable to perform DFM testing on non-AWT tested valves, based on a scientifically valid justification. In this situation, this "non-AWT DFM" is reasonable because the chief benefit of the test, for both tissue valves and mechanical valves, is from comparing the test valve with the reference valves when both have a known clinical behavior and a known DFM behavior. The damage caused during a normal AWT is typically insignificant compared with the damage caused by the extreme conditions used for a DFM.

For the pediatric scenarios, it is assumed that approved designs, which have previously qualified using the full array of FDA and ISO 5840 tests, will be scaled down to pediatric sizes, using identical materials. Because failure modes in the DFM are controlled by design, materials, and the pressure in the DFM, it is unlikely that new failure modes would be observed in this situation.

If new failure modes are observed in the pediatric size using a non-AWT DFM test, it should be required to run a standard AWT-DFM as a check against any unintended consequences from the design scaling.

Sewing ring integrity testing. The ISO 5840 and HVG documents suggest testing the sewing ring to demonstrate that the sewing ring will not become separated from the

TABLE 4. Pulsatile flow test conditions

\begin{tabular}{lccccc}
\hline $\begin{array}{c}\text { Pediatric } \\
\text { subpopulation }\end{array}$ & $\begin{array}{c}\text { Systolic } \\
\text { duration, } \%\end{array}$ & $\begin{array}{c}\text { Beat rate, } \\
\text { beats/min }\end{array}$ & $\begin{array}{c}\text { Cardiac output, } \\
\text { L/min }\end{array}$ & $\begin{array}{c}\text { Left-sided heart } \\
\text { MAP, mm Hg }\end{array}$ & $\begin{array}{c}\text { Right-sided } \\
\text { heart MAP, mm Hg }\end{array}$ \\
\hline Newborn & 50 & $60,150,200$ & $0.3,0.5,1,1.5$ & 45 & 20 \\
Infant & 50 & $60,120,200$ & $0.5,1,2,3$ & 55 & 20 \\
Toddler & 45 & $60,100,160$ & $1.5,3,4.5$ & 65 & 20 \\
Child & 40 & $60,80,140$ & $2,3.5,5$ & 80 & 20 \\
Adolescent & 35 & $45,70,120$ & $2,5,7$ & 100 & 20 \\
\hline
\end{tabular}

MAP, Mean arterial pressure. 
TABLE 5. Structural performance characterization

\begin{tabular}{lll}
\hline \multicolumn{1}{c}{ Test } & \multicolumn{1}{c}{ 1 Size down } & $\geq$ 2 Sizes down \\
\hline AWT & Table 7 recommendations at subpopulation pressures & Table 7 recommendations at subpopulation pressures \\
Stress and fatigue life analyses & Perform FEA for new size: perform life analysis on & Perform FEA for new sizes: perform life analysis on \\
& worst-case size for entire combined adult/pediatric & worst-case size for entire combined adult/pediatric \\
& size range & size range \\
Dynamic failure Mode test & Test worst-case size only, not necessarily after AWT & Test worst-case size only, not necessarily after AWT \\
& (justification required) & (justification required) \\
Sewing ring integrity testing & Test & Test all sizes \\
Design-specific testing & Test & Test all sizes \\
\hline
\end{tabular}

$A W T$, Accelerated wear testing; $F E A$, finite element analysis.

prosthetic heart valve, and that the ring will retain sutures under worst-case loading. This same testing is appropriate for pediatric sizes.

Design-specific testing. The ISO 5840 and HVG documents suggest performing additional appropriate designspecific testing, based on the nature of the prosthetic valve under consideration. The same design-specific testing previously performed on the adult sizes of the approved design is appropriate for the pediatric sizes.

\section{Other Categories of In Vitro Data to Support \\ a Premarket Approval Supplement Application}

For the information categories of sterilization validation, shelf-life testing, biocompatibility evaluation, microbiological testing, corrosion testing, and large-animal in vivo testing, it is reasonable to apply justifications based on previous testing for the adult sizes. The justifications would be based on using the same materials processed using the same methods and a scaled design from a previously approved adult valve.

\section{Revisions to ISO 5840 and the HVG}

This white paper uses testing described in ISO 5840:2005 and the 2010 FDA Draft Replacement HVG. From time to time, ISO standards are updated, and the HVG may at some time be finalized. If either or both of these cases occur, then the recommendations in this white paper will require consideration, on a case-by-case basis, depending on changes that might be applicable. However, because the pediatric heart valves addressed by this white paper are down-sized versions of valves previously approved for adults using ISO 5840 and the HVG, ongoing use of the 2005 and 2010 documents may continue to be appropriate.

TABLE 6. Minimum values for AWT peak differential pressure

\begin{tabular}{lcccc}
\hline \multirow{2}{*}{$\begin{array}{c}\text { Pediatric } \\
\text { subpopulation }\end{array}$} & \multicolumn{4}{c}{ Minimum peak differential pressure, mm Hg } \\
\cline { 2 - 5 } & Mitral & Aortic & Tricuspid & Pulmonary \\
\hline Newborn & 75 & 50 & 30 & 10 \\
Infant & 90 & 60 & 30 & 10 \\
Toddler & 97 & 67 & 30 & 10 \\
Child & 105 & 75 & 30 & 10 \\
Adolescent & 120 & 90 & 30 & 10 \\
\hline
\end{tabular}

$A W T$, Accelerated wear testing.

\section{CLINICAL DATA REQUIRED TO SUPPORT} A PREMARKET APPROVAL APPLICATION Rationale for Establishing the Clinical Benefit of a New Pediatric Replacement Heart Valve

The safety and effectiveness of a new heart valve replacement are clinically evaluated by 3 basic performance parameters, including hemodynamics, durability, and adverse event rates. During IDE* clinical trials, significant clinical data are collected to demonstrate clinical safety and effectiveness of a new heart valve design through adverse event and hemodynamic analysis, respectively. However, it is difficult to assess long-term valve durability based on the overall follow-up time during the IDE study.

As noted, pediatric heart valve replacement studies are difficult to conduct because of the smaller pediatric patient pool compared with the adult patient pool. Therefore, to mitigate this difficulty, a logical approach would be to design a smaller pediatric valve using the same materials, scaled down from a previously FDA-approved adult heart valve replacement design. By using this approach, a manufacturer would start with a proven record of clinical safety and effectiveness with the current heart valve replacement device. Because the pediatric valve design would be based on a clinically proven adult design with clinically proven materials, collected data would be focused on the use of the proven design in the pediatric patient population.

\section{Pediatric Clinical Trial Design}

The focus of an IDE pediatric clinical trial should be similar to standard IDE trials (assessing clinical safety and effectiveness). If a clinically proven design was selected, valve durability would already be established. Although new valve designs are outside the scope of this white paper, if a new valve design was selected, valve durability would need to be assessed (eg, in vitro and premarket and postmarket studies).

Clinical safety data and study design for the pediatric population should be focused on valve-related adverse

\footnotetext{
* Investigational Device Exemption (IDE), described in 21 CFR Part 12, Investigational Device Exemptions.
} 
TABLE 7. Pediatric AWT test duration recommendations

\begin{tabular}{lccc}
\hline & \multirow{2}{*}{$\begin{array}{c}\text { Life analysis cycle criterion } \\
\text { (equivalent years) }\end{array}$} & \multicolumn{2}{c}{ FEA peak differential pressure/cardiac output, mm Hg/L/min } \\
\cline { 2 - 4 } Pediatric subpopulation & 5 & Left side of the heart & Right side of the heart \\
\hline Newborn & 7 & $90 / 1.5$ & $40 / 1.5$ \\
Infant & 10 & $100 / 3$ & $40 / 3$ \\
Toddler & 15 & $110 / 4.5$ & $40 / 4.5$ \\
Child & 15 & $135 / 5$ & $40 / 5$ \\
Adolescent & 15 & $160 / 7$ & $40 / 7$ \\
\hline
\end{tabular}

$A W T$, Accelerated wear testing; $F E A$, finite element analysis.

event rates because there may be other comorbidities that could confound the adverse event profiles for the study. The preferred approach for collection of clinical data is a prospective clinical trial design. However, many clinical studies have been successfully completed with retrospective data. Because the pediatric patient population for heart valve dysfunction is somewhat limited, it may make sense to consider evaluation of retrospective clinical data or data from peer-reviewed published journals.

Methods of assessing hemodynamic parameters (eg, effective orifice area [EOA], EOA index, cardiac output, and cardiac index) in the pediatric population may differ from those in the adult population. For example, cardiac output and cardiac index are not routinely calculated in children. In addition, small errors in measuring the left ventricular outflow tract diameter lead to propagation of error in EOA calculation, and these larger errors are amplified in children when compared with the relatively small pediatric annulus dimensions. Hence, native valve area and prosthetic valve EOA calculation with the continuity equation are not commonly used in children, ${ }^{12}$ and new techniques for prosthetic valve evaluation (eg, 3-dimensional echo with planimetry and ejection fraction) are evolving. Therefore, the sponsor will have to work closely with the FDA to determine the appropriate hemodynamic assessments and techniques for the device and pediatric population under consideration.

For valve designs that are already clinically proved, the clinical data would be collected from at least 3 centers with data available on a minimum of 15 patients per valve size who have reached a minimum of 1 year of follow-up. The follow-up time points would be based on the standard of care (ie, within 30 days, 6 months, 1 year, and annually thereafter until the study ends). The proposed preoperative, operative, and postoperative data collected are described in Table 9. Long-term postapproval data may also be needed, as described later.

\section{Postmarket Clinical Data Requirements}

After market approval, the pediatric IDE patients should be observed in a postapproval study for a minimum of 5 years (or less if the valve is removed earlier). Sponsors should consider consent to the IDE cohort for more than 5 years to allow transition to the postapproval study with ease. After appropriate follow-up in the postapproval study, "conversion" to a sponsor registry follow-up would allow these patients to be observed long-term after heart valve replacement.

Additional postmarket data may also be collected beyond the IDE cohort. This collection could involve additional patient enrollment into the postapproval study, the sponsor registry, or, alternatively, a national registry. A national registry could be used to collect safety and effectiveness data across multiple sponsors with FDA-approved pediatric replacement heart valves. An example of such is the Congenital Cardiac Surgery Database maintained by the Society of Thoracic Surgeons.

\section{Summary}

There is a clear and urgent need for FDA-approved pediatric prosthetic heart valve devices in the United States. The example set by FDA leadership would likely lead to increased availability of pediatric devices in other regulated economies. An "orphan category" for such devices is an untenable scenario in the 21 st century. This white paper addresses important preclinical and premarket and postmarket clinical studies that should be considered by a heart valve manufacturer for obtaining regulatory approval of pediatric sizes of prosthetic heart valve designs already approved for adult clinical use. It is hoped that such a least-burdensome approach would lead to the approval of pediatric-sized mechanical and bioprosthetic valves in the next few years. This paradigm could be extended to other cardiovascular devices with pediatric applications.

TABLE 8. Pediatric FEA loading and life analysis recommendations

\begin{tabular}{lcc}
\hline $\begin{array}{c}\text { Pediatric } \\
\text { subpopulation }\end{array}$ & $\begin{array}{c}\text { Mechanical valves } \\
\text { (equivalent years) }\end{array}$ & $\begin{array}{c}\text { Tissue valves } \\
\text { (equivalent years) }\end{array}$ \\
\hline Newborn & 5 & 2 \\
Infant & 7 & 5 \\
Toddler & 10 & 5 \\
Child & 15 & 5 \\
Adolescent & 15 & 5 \\
\hline
\end{tabular}

FEA, Finite element analysis. 
TABLE 9. Clinical study data for pediatric heart valves

\begin{tabular}{|c|c|c|}
\hline Preoperative & Operative & Postoperative \\
\hline Diagnosis & Concomitant procedures & Date of follow-up \\
\hline Patient age/sex & Patient age & Patient age \\
\hline Height/weight/body surface area & Height/weight/body surface area & Height/weight/body surface area \\
\hline Previous cardiovascular procedures & Date of implant & $\begin{array}{l}\text { Core laboratory-evaluated echocardiographic } \\
\text { hemodynamic data* }\end{array}$ \\
\hline $\begin{array}{l}\text { Comorbidities (known genetic syndromes and major } \\
\text { noncardiac diseases) }\end{array}$ & Implant position & Anticoagulant/antiplatelet regimen \\
\hline $\begin{array}{l}\text { Type of valvular lesion (ie, stenosis, regurgitation, or } \\
\text { mixed stenosis/regurgitation) }\end{array}$ & Valve-related adverse events & Valve-related adverse events \\
\hline
\end{tabular}

Cause of valvular lesion (eg, calcification/

degeneration, congenital, rheumatic, or infectious)

NYHA functional classification, if study patients are adolescent patients and such data are available. For infants and toddlers, Ross Scale functional classification should be provided if available. $\dagger$

NYHA functional classification, if study patients are adolescent and such data are available. For infants and toddlers, Ross Scale functional classification should be provided if available. $\dagger$

Blood collection specific to hemolysis

Spot urine urobilinogen collection may be used in place of blood collection for hemolysis evaluation for pediatric populations

NYHA, New York Heart Association. *For aortic and mitral valve replacement patients: peak gradient, mean gradient, performance index, valvular regurgitation, and ejection or shortening fraction. Effective orifice area and effective orifice area index should be considered. For pulmonic and tricuspid valve replacement patients: peak gradient, mean gradient, and valvular regurgitation. †Data from Ross RD, Bollinger RO, Pinsky WW. Grading the severity of congestive heart failure in infants. Pediatr Cardiol. 1992;13:72-5.

We thank Dr Bram D. Zuckerman and Fernando Aguel at the FDA for the collaboration and continuing dialogue in preparing this article.

\section{References}

1. Karamlou T, Jang K, Williams WG, Caldarone CA, Van Arsdell G, Coles JG, McCrindle BW. Outcomes and associated risk factors for aortic valve replacement in 160 children. Circulation. 2005;112:3462-9.

2. Schmidt P. A new paradigm for obtaining marketing approval for pediatric sized prosthetic heart valves: engineering breakout session summary presentation. Pediatric Heart Valve Workshop; January 12, 2010; Washington, DC.

3. Vidmar S. A new paradigm for obtaining marketing approval for pediatric sized prosthetic heart valves: clinical breakout session summary presentation. Pediatric Heart Valve Workshop; January 12, 2010; Washington, DC.

4. US Food and Drug Administration, Center for Devices and Radiological Health. Pediatric expertise for advisory Panels: guidance for industry and FDA staff. Silver Spring, MD: US Food and Drug Administration; 2003.

5. International Organization of Standardization. Cardiovascular implantscardiac valve prostheses. ISO 5840:2005.

6. US Food and Drug Administration, Center for Devices and Radiological Health. Draft guidance for industry and FDA staff: heart valves-investigational device exemption (IDE) and premarket approval (PMA) applications. Available at: http://www.fda.gov/MedicalDevices/DeviceRegulationandGuidance/Guidance Documents/ucm193096.htm. Accessed March 10, 2013.

7. Greene MG. The Harriet Lane Handbook. 12th ed. St Louis, MO: Mosby Yearbook; 1991.

8. Kliegman RM, Stanton BMD, St Geme J, Schor N, Behrman RE. Nelson Textbook of Pediatrics. 17th ed. Amsterdam, The Netherlands: Elsevier Science; 2003.

9. Sarnari R, Kamal RY, Friedberg MK, Silverman NH. Doppler assessment of the ratio of the systolic to diastolic duration in normal children: relation to heart rate, age, and body surface area. J Am Soc Echocardiogr. 2009;8:28-32.

10. Knirsh W, Kretschmar O, Tomaske M, Stutz K, Nagdyman N, Balmer C, et al. Cardiac output measurement in children: comparison of the Ultrasound Cardiac Output Monitor with thermodilution cardiac output measurement. Intensive Care Med. 2008;34:1060-4.

11. Seear M, Webber S, Leblanc J. Descending aortic blood flow velocity as a noninvasive measure of cardiac output in children. Pediatr Cardiol. 1994;15: 178-83.

12. Doddamani S, Bello R, Friendman MA, Banerjee A, Bowers JH Jr, Kim B, et al. Demonstration of left ventricular outflow tract eccentricity by real time $3 \mathrm{D}$ echocardiography: implications for the determination of aortic valve area. Echocardiography. 2007;24:860-6. 